\title{
Cumulative Damage Evaluation under Fatigue Loading
}

\author{
L. E. Granda Marroquín ${ }^{1, a}$, L. H. Hernández-Gómez ${ }^{1, b}$, \\ G. Urriolagoitia-Calderón ${ }^{1, c}$, G Urriolagoitia-Sosa ${ }^{2, d}$ \\ and E. A. Merchan-Cruz ${ }^{2, e}$
}

\author{
${ }^{1}$ INSTITUTO POLITECNICO NACIONAL \\ Sección de Estudios de Posgrado e Investigación (SEPI), Escuela Superior de Ingeniería \\ Mecánica y Eléctrica (ESIME). Edificio 5. 2ํ Piso, Unidad Profesional Adolfo López Mateos \\ "Zacatenco" Col. Lindavista, C.P. 07738, México, D.F. México \\ ${ }^{2}$ INSTITUTO POLITECNICO NACIONAL \\ Sección de Estudios de Posgrado e Investigación (SEPI), Escuela Superior de Ingeniería \\ Mecánica y Eléctrica (ESIME). Unidad profesional, Azcapotzalco, \\ Av. de las Granjas No. 682, Col. Sta. Catarina Azcapotzalco, C.P. 02550, México \\ algranda2000@yahoo.com.mx, luis.granda@dana.com, luishector56@hotmail.com, \\ curri332@hotmail.com, ${ }^{\mathrm{d}}$ guiurri@hotmail.com, ${ }^{\mathrm{e}}$ eamerchan@ipn.mx
}

Keywords: Cumulative damage, Continuum Damage Mechanics, fatigue, damage curves, axle.

\begin{abstract}
The goal of this paper is to present the results obtained from damage evaluation in automotive axles, which are under torsion fatigue. For this purpose, a Nonlinear Damage Model is used. The mentioned shafts have to satisfy geometry requirements and their material has to be heat treated in order to improve their performance. One has to keep in mind that fatigue strength depends on material properties and geometry. In order to make a precise evaluation of the accumulated damage, the manufactured shafts were tested. In the first instance, the mechanical properties of the material were evaluated with static torsion tests. In the next step, the S-N curves were obtained with torsion fatigue tests. In all these cases, temperature was controlled. Experimental data at different load levels was gathered with strain gages in conjunction with a data acquisition system. The life cycle history of each tested shaft was stored and with this experimental evidence, damage curves were obtained and the cumulative damage of the axle was established. With these damage curves, it is possible to define the relation between damage rate and life for different stress levels.
\end{abstract}

\section{Introduction}

In the last 25 years, the quality of manufactured products in the automotive industry has been improved, because global competition has increased. In the case of automotive axles, they have to be tested in order to evaluate their fatigue resistance and satisfy the different customer requirements. The goal is to guarantee their correct functionally.

Miner's rule [1] was the first linear damage model proposed. It is widely used. However, it often leads to non-conservative life predictions. Since its introduction, different fatigue damage theories have been proposed, in order to improve the accuracy of fatigue life prediction. In the 1950s, Manson [2] and Coffin [3] proposed that plastic strain is one of the main causes of cyclic damage in metals. Chaboche [4] established that fatigue damage can be described by means of an internal variable. Lemaitre [5] takes into account thermodynamic principles. With these concepts, the effects associated with a given damage state are described. In addition to this, several nonlinear models have been proposed. Their purpose is the accurate description of damage evolution in different metals.

Accordingly, the purpose of this paper is the prediction of fatigue damage of an automotive axle, which is subjected to variable loading. The shaft is under diverse shear stresses, which cause fatigue. Observations have shown that there is a localized damage process, which is the result of a 
cumulative damage process. In other words, during cyclic loading, localized plastic deformation may occur at the highest stress site. This plastic deformation induces permanent damage to the component and a crack is initiated. As the number of loading cycles is increased, damage grows. After a certain number of cycles, a crack is developed and, at the end, the final failure of the shaft ocurrs.

\section{Statement of the problem}

The automotive axle, which was analyzed, is shown in Fig.1. It is used in the power transmission system in a heavy truck. It is made with SAE 1038 steel with induction heat treatment. The axle has three main parts, the flange, the forge body and the spline. The complete component is under torsion load. However, the spline and the zone close to it are under maximum shear stress. Consequently, the main cause of failure in the spline zone is fracture by shear stress (Fig.2). Currently, the fatigue life of this shaft is established by static analysis, safety factors and fatigue analysis (experimental and numerical). Nonetheless, the automotive behavior is so complex. For this reason, the purpose of this work is the development of the damage evolution curves, using a nonlinear damage model. Concepts of the Continuum Damage Mechanics (CDM) are taken into consideration in order to explain the results obtained.

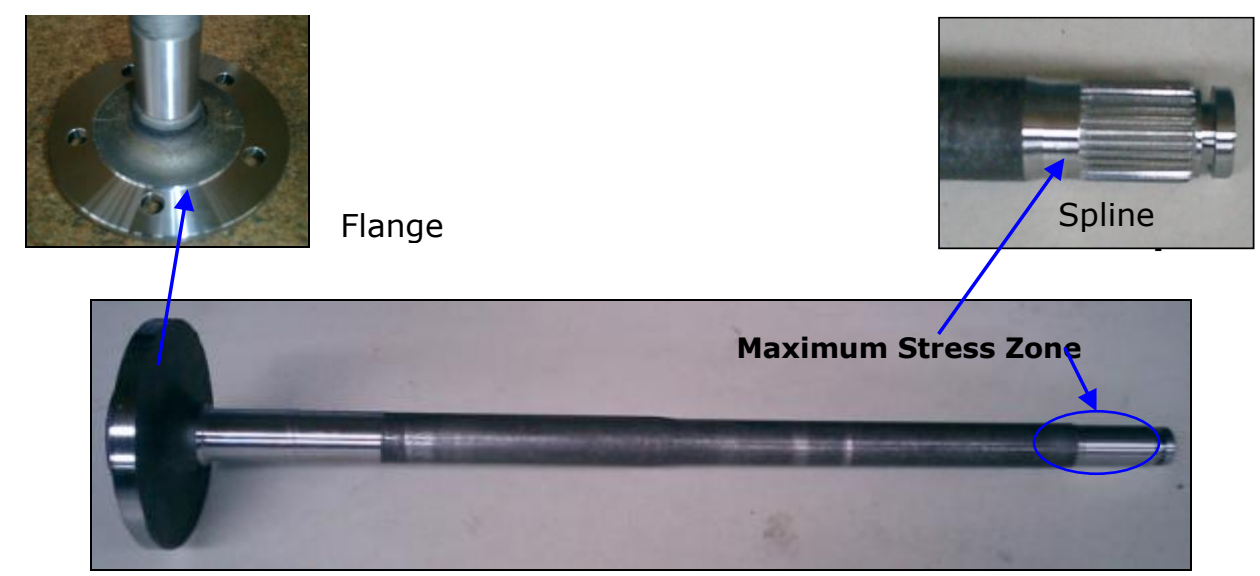

Fig.1. Automotive axle.

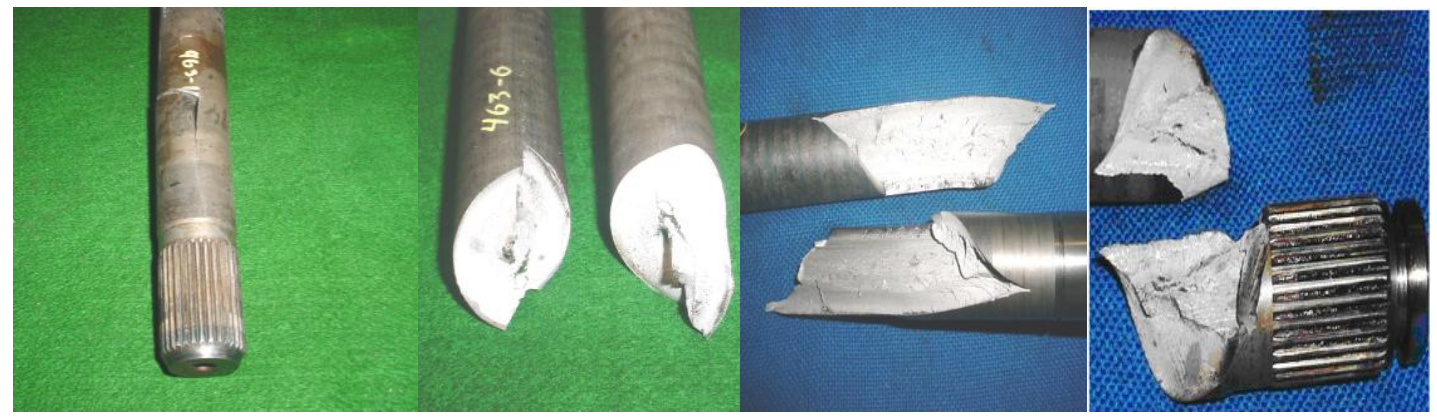

Fig. 2, Shaft failure. 
Table 1. Nomenclature

\begin{tabular}{|llll|}
\hline$\sigma_{f}^{i}$ & Fatigue strength coefficient & $E$ & Young's modulus $\tilde{E}$ \\
$\mathrm{~b}$ & Fatigue strength exponent & $\tilde{E}$ & Damaged Young's modulus \\
$\Delta \sigma$ & Cyclic stress range & $D$ & Damage parameter \\
$\sigma_{e q}$ & Effective stress & $N$ & Number of cycles \\
$\Delta \varepsilon_{p}$ & Plastic strain range & $N_{f}$ & Cycles to failure \\
$\Delta \varepsilon_{e}$ & Elastic strain range & $n_{1}$ Cycles under a load $\sigma_{1}$ \\
$\varepsilon_{f}^{i}$ & Fatigue ductility coefficient & $n_{2}$ Cycles under a load $\sigma_{2}$ \\
$v$ & Poisson's ratio & $N_{1}$ Cycles to failure under a load $\sigma_{1}$ \\
$K^{i}$ & Cyclic strength coefficient & $N_{2}$ Cycles to failure under a load $\sigma_{2}$ \\
\hline
\end{tabular}

\section{Theoretical Background}

Fatigue Damage Mechanism. In general terms, it has been observed that the fatigue process involves the following stages: (1) crack nucleation, (2) short crack growth, (3) long crack growth and (4) final fracture. Regarding the nucleation stage, it is the first step in the fatigue process. Cracks start on a localized shear plane at or near high stress concentrations, such as persistent slip bands, inclusions, porosity or discontinuities. In the case of the axle, the localized shear plane usually occurs at the surface or within grain boundaries. Once nucleation occurs and cyclic loading continues, the crack tends to grow along the plane of maximum shear stress and through the grain boundary.

The next step in the fatigue process is the crack growth stage. Crack nucleation and growth are usually considered to be the initial short crack propagation across a finite length. This is of the order of a couple of grains on the maximum local shear stress plane. In this stage, the crack tip plasticity is greatly affected by the grain size, orientation, and stress level, because the crack size is comparable to the material microstructure.

In the long crack growth stage, crack propagation is normal to the maximum principal stress. The long crack is less affected by the properties of the microstructure than in the first stage. This is because the crack tip plastic zone is larger than the material microstructure. When this is completed, stage 4 is present, the final fracture.

In engineering applications, crack nucleation takes some part of the fatigue life (see Fig.3). An exact definition of the transition period from initiation to propagation is usually not possible. However, for steels, the size of a crack at the end of the initiation stage is of the order of a couple of grains of the material. Typically, the crack initiation takes more time, particularly in the high fatigue cycle regime (approximately $>10,000$ cycles). Alternately, in the low cycle fatigue regime (approximately $<10,000$ ), most of the fatigue life is spent on crack propagation. 


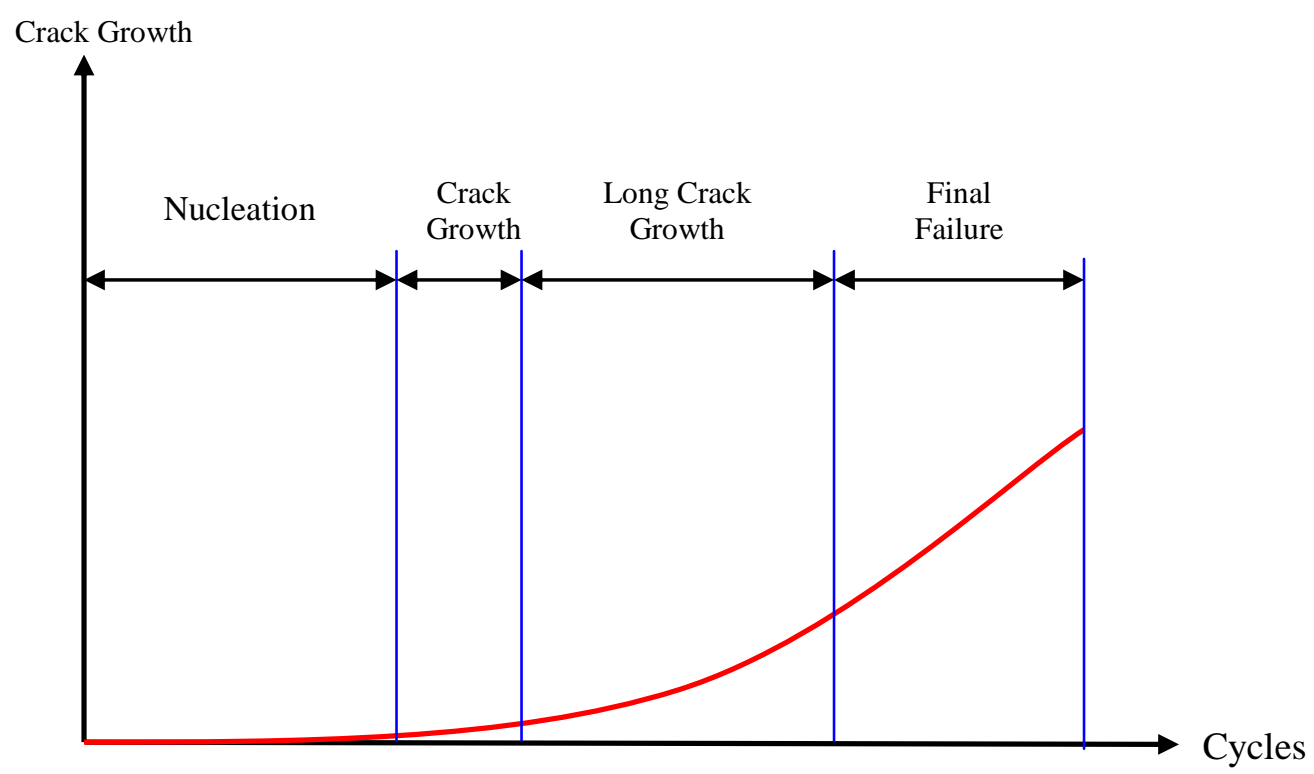

Fig.3. Fatigue cycles vs. crack growth.

Basic concept of CDM. An important concept is damage, which is considered as a thermodynamic variable. It is assumed that it is responsible for progressive material deterioration. Lemaitre [6] defined it, in terms of the resistance reduction of a Reference Volume Element (RVE) thus:

$D_{V}=\frac{\delta V_{\text {vacios }}}{\delta V_{E V}}=f_{V}$

From a scalar point of view, Kachanov [7] established that in isotropic materials, damage is defined by:

$D=\frac{\delta S_{D}}{\delta S}$

The Effective Stress Concept is defined by the following equation. In this case, the constitutive equation for damage considers that there are surface discontinuities.

$\tilde{\sigma}_{i j}=\frac{\sigma_{i j}}{1-D}$

The uniaxial law of elasticity for isotropic damage is represented by:

$\varepsilon_{e}=\frac{\sigma}{E(1-D)}=\frac{\sigma}{\widetilde{E}}$

Damage is expressed as a loss of stiffness, as follows:

$D=1-\frac{\widetilde{E}}{E}$

Nonlinear damage model. The linear damage model $\left(\sum D_{i}=\sum\left(n_{i} / N_{i, f}\right) \geq 1.0\right)$ was proposed initially. It is an un-conservative model. Therefore, in this paper, a nonlinear model has been used in the development of damage curves. The following calculation procedure was used. Initially, a two-step high-low sequence loading was considered. In this case, $\mathrm{n}_{1}$ is the initial number of load cycles, which are applied at a higher stress level. On the other hand $n_{2, f}$ are the remaining cycles, which eventually cause fatigue failure at lower stress level. One has to keep in mind that the S-N curve is used to obtain the fatigue lives $\mathrm{N}_{1, \mathrm{f}}$ and $\mathrm{N}_{2, \mathrm{f}}$ for each load level. The following equations are the relations between the cycle ratio $n_{1} / N_{1, f}$ and the equivalent damage cycle ratio $n_{2} / N_{2, f}$ :

$\left(n_{2, f} / N_{2, f}\right)=1-\left(n_{1} / N_{1, f}\right)^{\left(N_{1, f} / N_{2, f}\right)^{0.4}}$ 


$$
\frac{n_{1}}{N_{1, f}}=\left[\frac{n_{2}}{N_{2, f}}\right]^{\left(N_{1, f} / N_{2, f}\right)^{0.4}}
$$

Eq. 7 is independent of material and geometry parameters. Based on this argument, a nonlinear damage curve, for a reference life defined previously $\left(N_{1, f}\right)$, can be linearized. Therefore, a damage curve for multiple life levels $\left(N_{1, f}<N_{2, f}<\ldots \ldots . .<N_{n, f}\right)$ is then given by the damage law equation, defined as:

$D_{n+1}=\left[\frac{n_{n+1}}{N_{(n+1), f}}\right]^{\left(N_{(n+1)} / N_{(n+1), f}\right)^{0.4}}$

Subramanyan [8] established a damage law equation based on experimental data, which is taken from the S-N curve. The calculated damage, as a function of the stress amplitude and the fatigue limit $\left(S_{r e f}, S_{e}\right)$, is:

$D_{N}=\left[\frac{n_{n}}{N_{n, f}}\right]^{\left(S_{n}-S_{e}\right) /\left(S_{r e f}-S_{e}\right)}$

In 1980, Hashin [9] defined a damage equation. In this case, fatigue life $N_{e}$ is used instead of fatigue limit $S_{e}$. The resultant equation is:

$$
D_{N}=\left[\frac{n_{n}}{N_{n, f}}\right]^{\log \left(N_{n, f} / N_{e}\right) / \log \left(N_{r e f} / N_{e}\right)}
$$

After analyzing these theoretical concepts, it can be said that three alternatives can be followed to determine damage evolution. They are represented with eqs. 8,9 and 10 . In the case of this work, it was selected eq. 8 , because a good accuracy can be obtained with static and fatigue tests.

\section{Experimental Analysis}

In order to evaluate damage in the shaft, static torsion and fatigue tests were carried out in accordance with ASTM [10]. The static tests were done in a static torsion machine Tinnus Olsen (Fig.4), while the fatigue testing was done in a fatigue torsion machine MTS-20K, 50K, 100K (Fig.5). Strains were recorded with

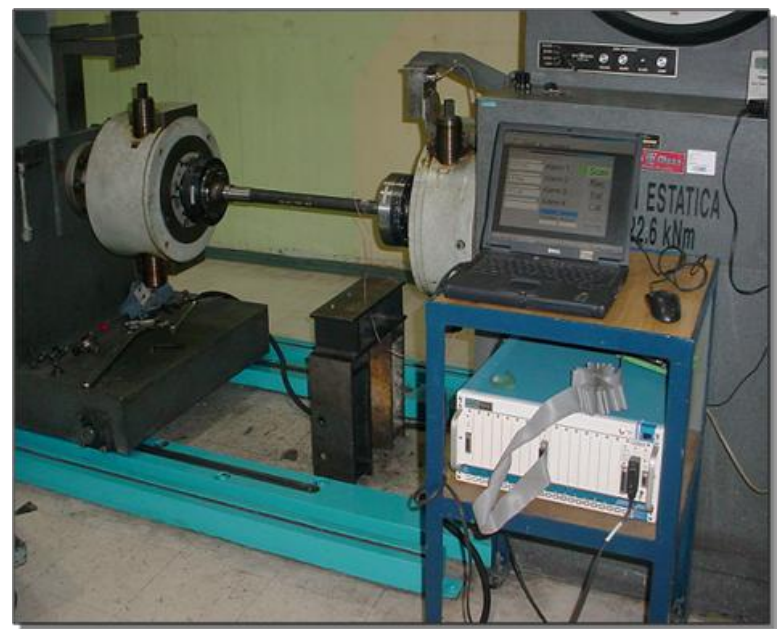

Fig.4 Static torsion and data acquisition system

Megadac equipment using strain gauge for torsion tests (CEA-06-187UV-350). 
As shear stress is expected, the strain gauges were fixed at $45^{\circ}$ from the axis. DANA No. 7 [11] procedure for static torsion was followed. The speed of the torsion torque was 20 degrees/min and 40 specimens were tested.

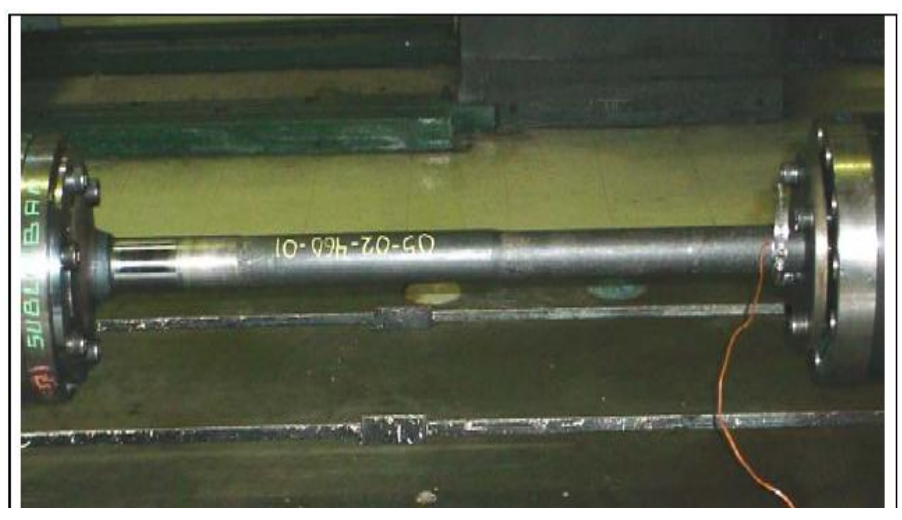

Fig.5a Fatigue torsión machine.

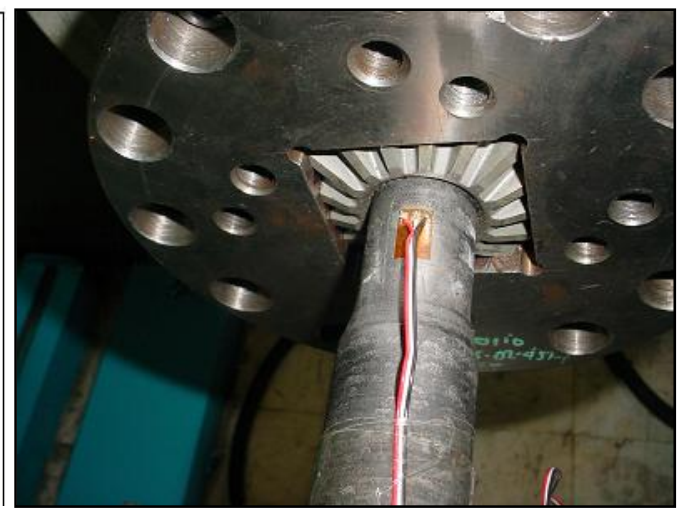

Fig.5b Strain gage arrangement.

In the case of the fatigue torsion tests, the strain gauges were fixed to the specimen as described above. Fig. 5 illustrates this arrangement. DANA No. 4 [12] procedure was followed. The frequency of the fatigue load was $4 \mathrm{~Hz}$, following a sinusoidal function. All the tests were done at $40^{\circ} \mathrm{C}$ and 50 specimens were tested.

\section{Experimental results}

The experimental parameters of

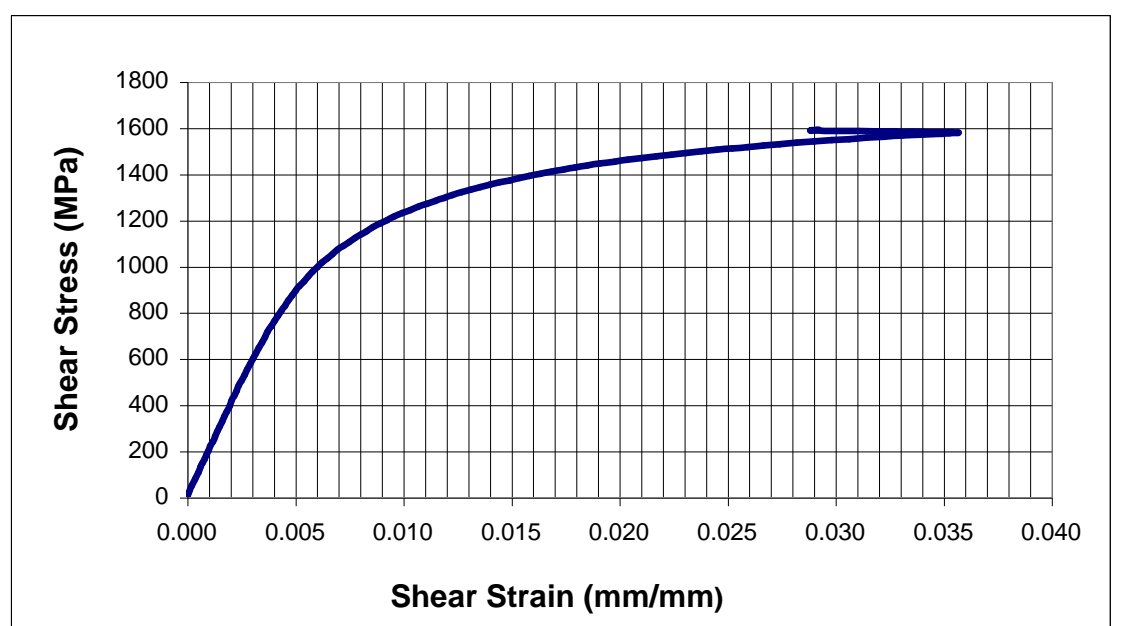

Fig.6 Typical stress-Strain Diagram for axle shaft SAE 1038. the static and fatigue tests are summarized in Table 2. Besides, Fig. 6 shows a typical stress strain curve obtained under static loading, while the S-N diagram is shown in Fig. 7.

\section{Damage Curves}

Damage curves for high and low fatigue cycles represent the damage evolution at different stress levels. These results were obtained with a nonlinear damage model, considering the experimental data obtained in the fatigue tests and using eqs. 6, 7 and 8. The nonlinear model was chosen, because its results are more conservative than those calculated with a linear model. 
Damage evolution curves for low fatigue cycles. Low cycle fatigue is characterized by a reduced number of cycles $(0-10,000$ cycles $)$ in which there are high stress levels with plastic strains. For this reason, this analysis is focused in the stress range, whose upper limit is the ultimate strength and its lower limit is $830 \mathrm{MPa}$ (close to the yield point). Table 3 summarizes parameters for damage curves related to low cycle fatigue.

Considering the damage evolution

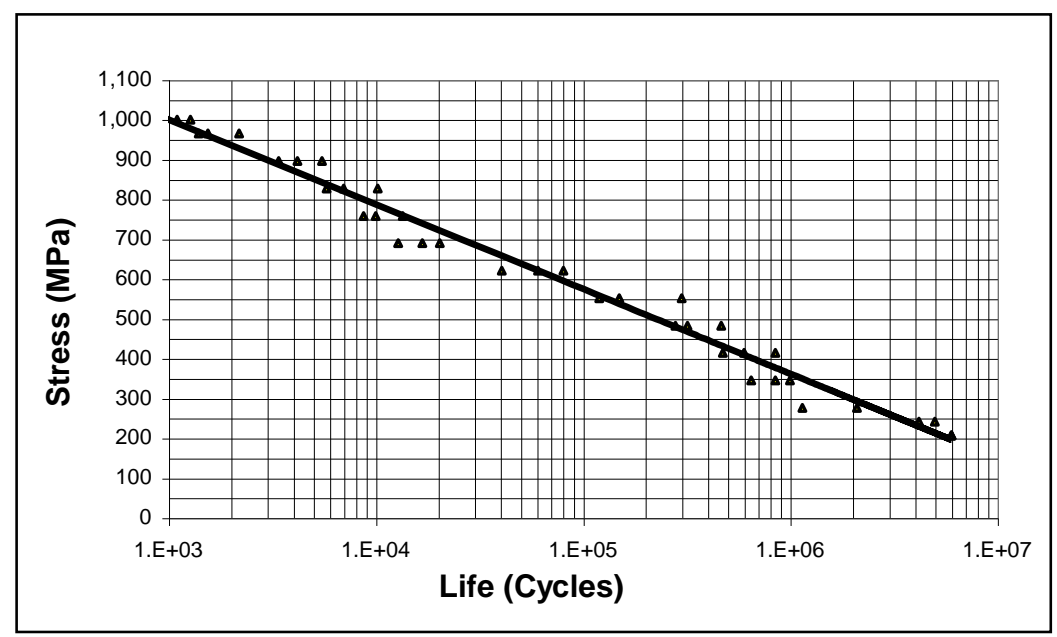

Fig.7 S-N Diagram axle shaft SAE 1038

illustrated in Fig. 3, three stages are identified. In the early stage, there is a plateau. It can be said that nucleation conditions are developed. This is followed by a transition phase, which is non linear. In this case crack initiation and crack growth take place. In a final stage, the damage curve is steeper. These conditions lead to failure. All these concepts were considered in the development of Tables 3 and 4 and approximate boundaries of each stage are proposed.

Table 2. Experimental parameters

\begin{tabular}{|l|l|}
\hline Static parameters & Fatigue parameters \\
$\mathrm{G}=207 \mathrm{GPa}$ & $\mathrm{S}_{\mathrm{e}}=235 \mathrm{MPa}$ \\
$\mathrm{E}=79.3 \mathrm{GPa}$ & $\sigma_{f}^{i}=1500 \mathrm{MPa}$ \\
$V=0.292$ & $\mathrm{~b}=-0.14$ \\
$\mathrm{~S}_{\mathrm{y}}=1100 \mathrm{MPa}$ & $\mathrm{c}=-0.57$ \\
$\mathrm{~S}_{\mathrm{u}}=1500 \mathrm{MPa}$ & $\varepsilon_{f}^{i}=0.61$ \\
$\varepsilon_{e}=0.007$ & $\varepsilon_{\text {threshold }}=\varepsilon_{\text {thr }}=0.005$ \\
$\varepsilon_{p}=0.032$ & \\
\hline
\end{tabular}

Table 3. Parameters of damage curves for low cycle fatigue.

\begin{tabular}{|c|c|c|c|}
\hline $\begin{array}{c}\text { Stress level } \\
{[\mathrm{MPa}]}\end{array}$ & $\begin{array}{c}\text { Nucleation } \\
{[\text { cycles] }}\end{array}$ & $\begin{array}{c}\text { Crack growth } \\
{[\text { cycles] }}\end{array}$ & $\begin{array}{c}\text { Fracture } \\
{[\text { cycles] }}\end{array}$ \\
\hline 1200 & $0<\mathrm{N}<20$ & $20<\mathrm{N}<600$ & $600<\mathrm{N}<1000$ \\
\hline 1050 & $0<\mathrm{N}<40$ & $40<\mathrm{N}<700$ & $700<\mathrm{N}<1200$ \\
\hline 900 & $0<\mathrm{N} 250$ & $250<\mathrm{N}<3250$ & $3250<\mathrm{N}<4500$ \\
\hline 830 & $0<\mathrm{N}<600$ & $600<\mathrm{N}<5600$ & $5600<\mathrm{N}<7000$ \\
\hline
\end{tabular}

Damage curves for low cycle fatigue were obtained (Fig.8). In this range, material deterioration is quick and plastic strains are developed. Two of these curves are close to ultimate strength (1200 $\mathrm{MPa}$ and $1050 \mathrm{MPa}$ ). It is important to note that damage evolution seems to behave linearly. That is, nucleation requires a reduced number of cycles, around 20 to 40 cycles (Table 3) and crack propagation takes place during most part of the fatigue life. The other two curves show the damage evolution close to the yield point (900 MPa and $830 \mathrm{MPa})$. As the stress level is reduced, non-linear behavior is observed and the fatigue life is increased. More cycles are required for nucleation and crack growth. 


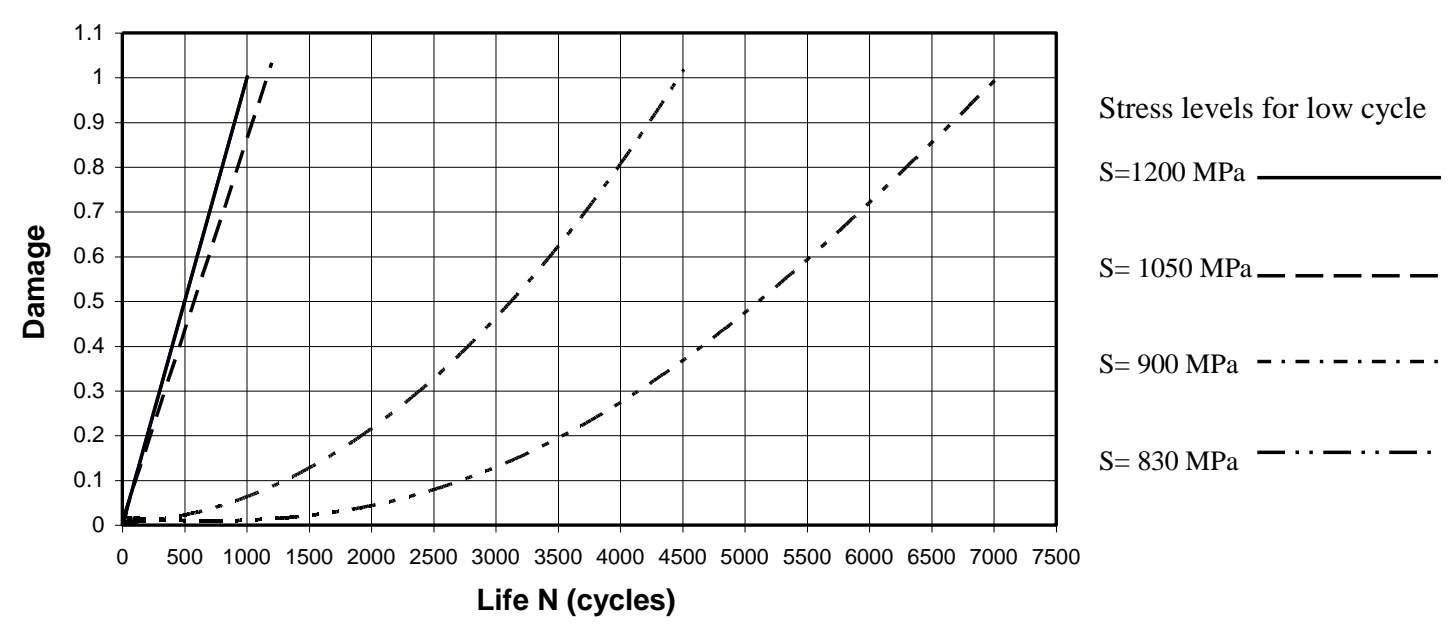

Fig.8 Damage-Life diagram for low cycle fatigue and high stress (SAE 1038 axle).

Damage evolution curves for high fatigue cycles. The lower limit of the high cycle fatigue range is considered between $10^{5}$ and $10^{6}$ cycles. Under this consideration, three stress levels were considered (400 MPa, $350 \mathrm{MPa}$ and $275 \mathrm{MPa}$ ). In this circumstance, elastic strain is predominant and nucleation takes several cycles, before plastic strain and crack initiation take place. Fig. 9 shows the material behavior in the last stage of the fatigue life. It takes place in a range, which is bigger than 500000 cycles. Also, it can be said that the working conditions of the axle is within this range.

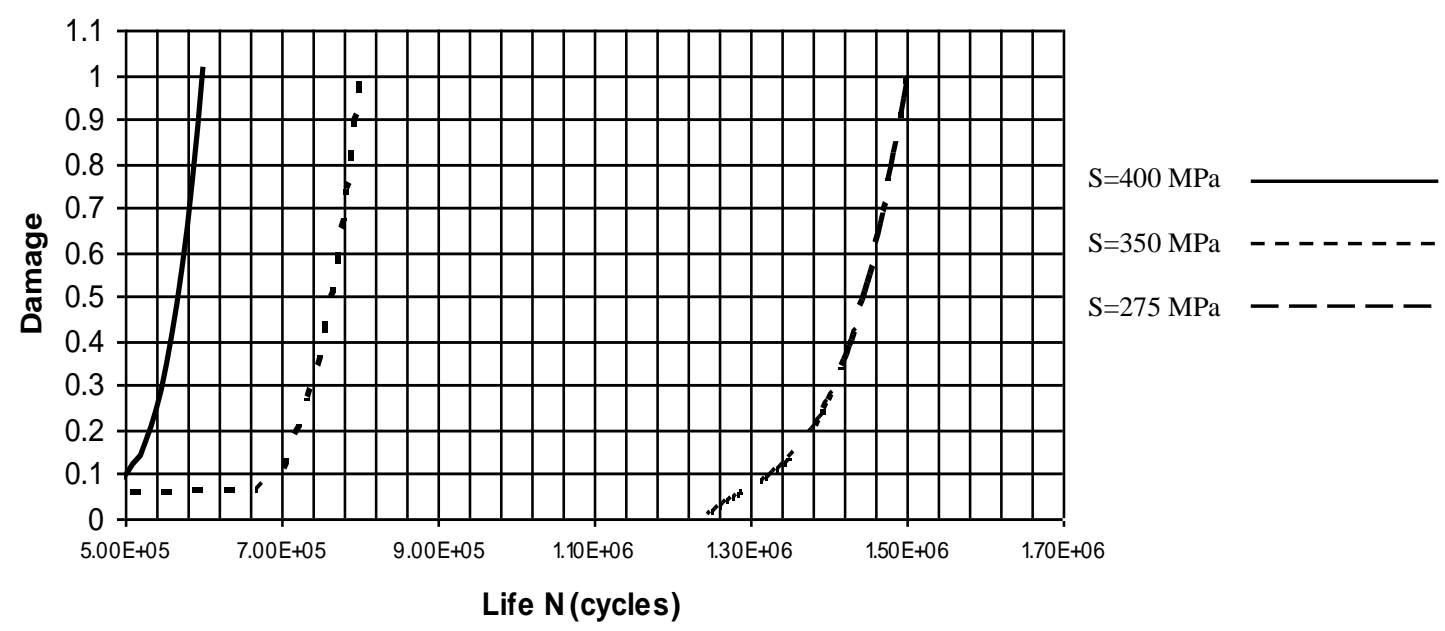

Fig. 9 Damage-Life diagram for high cycle fatigue and low stress (SAE 1038 axle).

Table 4. Damage curves parameter for high cycle fatigue.

\begin{tabular}{|c|c|c|c|}
\hline $\begin{array}{c}\text { Stress level } \\
{[\mathrm{MPa}]}\end{array}$ & $\begin{array}{c}\text { Nucleation } \\
{[\text { cycles] }}\end{array}$ & $\begin{array}{c}\text { Crack growth } \\
\text { [cycles] }\end{array}$ & $\begin{array}{c}\text { Fracture conditions } \\
\text { [cycles] }\end{array}$ \\
\hline $400 \mathrm{MPa}$ & $0<\mathrm{N}<350000$ & $350000<\mathrm{N}<560000$ & $560000<\mathrm{N}<600000$ \\
\hline $350 \mathrm{MPa}$ & $0<\mathrm{N}<655000$ & $655000<\mathrm{N}<765000$ & $765000<\mathrm{N}<800000$ \\
\hline $275 \mathrm{MPa}$ & $0<\mathrm{N}<1250000$ & $1250000<\mathrm{N}<1400000$ & $1400000<\mathrm{N}<1500000$ \\
\hline
\end{tabular}


Analisys of the damage rate. In order to complement the analysis of the results obtained, damage rate curves for low cycle were calculated (Fig. 10). This graph shows the relation between damage and ni/Nf cycles.
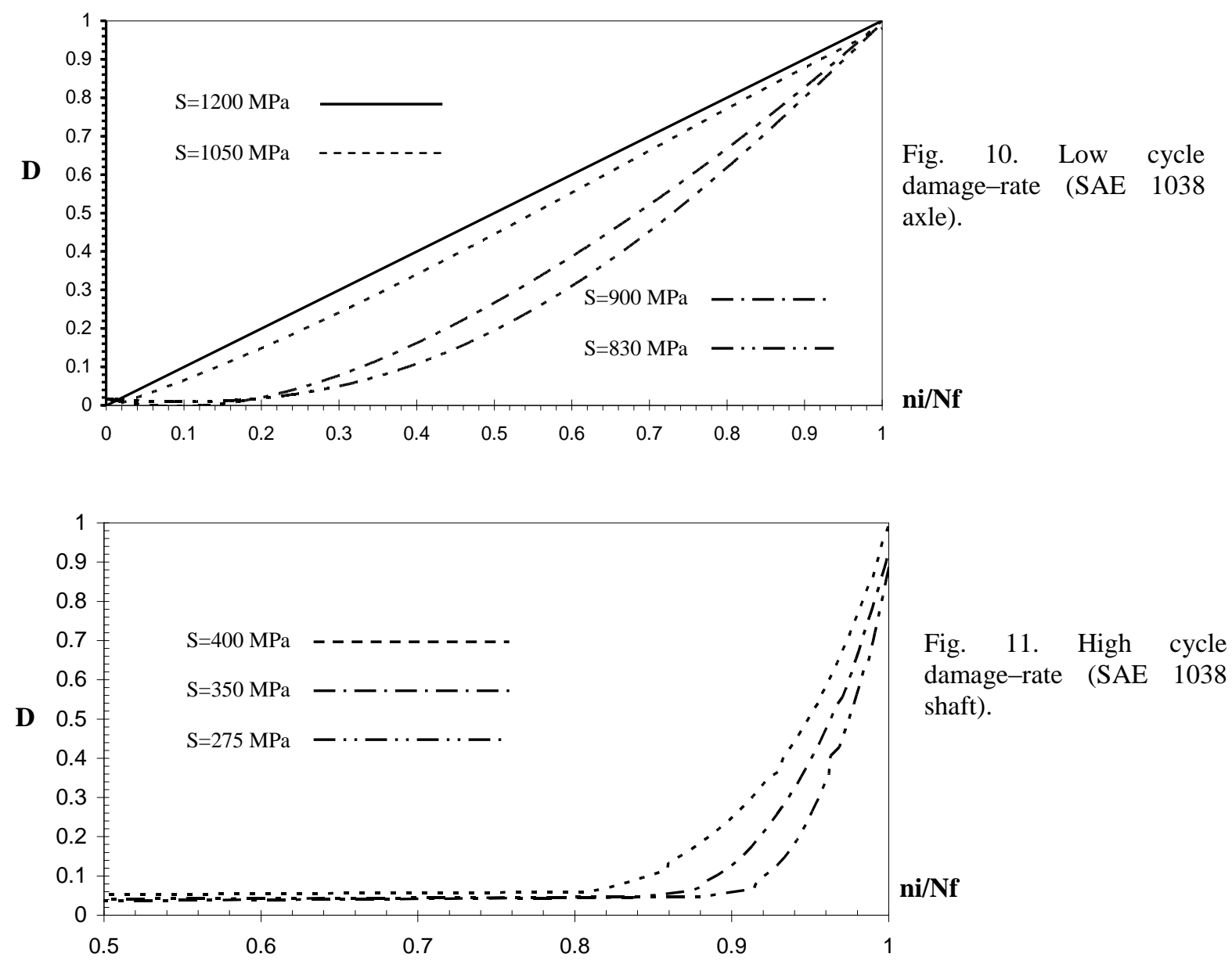

Fig. 10 confirms that for stresses above the material yield point, damage develops immediately. In the cases for the stress curves of $1200 \mathrm{MPa}$ and $1050 \mathrm{MPa}$, their slope is almost constant during the whole loading process. When the stress level is reduced (900 $\mathrm{MPa}$ and $830 \mathrm{MPa}$ ), the damage rate is low in the initial stage. There is a transition region. It takes place when ni/ $\mathrm{Nf}$ is 0.2 . Above this point, damage increases at bigger rates.

Fig. 11 shows the damage-rate behavior for high cycle. Below ni/Nf $=0.6$, damage rate is low. This situation is maintained until the inflection point is reached. In the case of $400 \mathrm{MPa}$, this point may be considered when ni/Nf is 0.82 . After that, the slope of this curve is stepper, leading to the final fracture. This transition zone moves towards the right, as the stress level is reduced. 


\section{Conclusions}

Damage and damage rate was estimated following a nonlinear model with the experimental evidence gathered. For this purpose, eqs. 6, 7 and 8 were used. Damage evolution was estimated straightforward with the experimental evidence gathered. In this case, the automotive shafts were tested. As a result, its physical and geometric characteristics were introduced in the evaluation. With all this information, it was possible to develop the Damage-Life diagrams at different stress levels. Although, it is possible to establish the damage evolution, it is not clear when the damage rate is severe.

Damage rate varies with the stress level. For low cycle, damage rate increases quickly. On the other hand, under high cycle fatigue, the rate of the material deterioration is small during most of the fatigue life. In fact, damage rate increases sharply at the end of the fatigue life.

The axles operate within this range, therefore, it is not expected that problems could arise in this situation. Special care should be considered in the final part of the fatigue life, as the rate of deterioration increases piercingly.

\section{Acknowledgements}

The support given by IPN, DANA MÉXICO, COFAA and CONACyT for the development of this work is kindly acknowledged

\section{References}

[1] M. Miner: Cumulative Damage Fatigue, J. App. Mech 12, (1945) A-159.

[2] S. Manson: Behavior of Materials under Conditions of Thermal Stress, In Heat Transfer Symposium, University of Michigan Engineering Research Institute, MI. p. 9-75.

[3] L. Coffin: The Stability of Metals under Cyclic Plastic Strain, Transaction American Society. Mechanical Engineers. (1954) p. 82.

[4] J. L. Chaboche: Continuum Damage Mechanics (Part I and II), J. Appl. Mech., vol.55, no.1, (1988) 59-72.

[5] J. Lemaitre: Engineering Damage Mechanics, Springer-Verlag Berlin Heidelberg, (2005) p.712.

[6] J. Lemaitre: Engineering Damage Mechanics, Springer-Verlag Berlin Heidelberg, pag. (2005) p. $1-5$.

[7] L. M. Kachanov: Introduction to Continuum Damage Mechanics, Martinus Nijhoff Publishers, (1986).

[8] S. Sbramanyan: Cumulative Damage Rule Based on the Knee Point of the S-N Curve, Journal of Engineering Materials and Technology, Vol. 98, (1976) p. 316 - 321.

[9] Z. A. Hashin: A reinterpretation of the Palmgren-Miner rule for Fatigue Life Prediction, Journal of Applied Mechanics, Vol. 47 (1980) p. 324 - 328.

[10] Annual Books of ASTM Standards: Section 3, Metals Test Methods and Analytical Procedures, Volume 03.01, (1998).

[11] DANA Corp. Spicer Axle Group: Torsional Test Procedure 7, pag. 4-9.

[12] DANA Corp. Spicer Axle Group: Torsional Test Procedure 4, pag. 1-4. 